\title{
QUALIDADE FISIOLÓGICA DE SEMENTES DE ARROZ TRATADAS COM SOLUÇÃO SALINA E 24-EPIBRASSINOLÍDEO ${ }^{1}$
}

\author{
CRISTINA FERREIRA LARRÉ2; DARIO MUNT DE MORAES ${ }^{3}$; NEI FERNANDES LOPES ${ }^{3}$
}

\begin{abstract}
RESUMO - Os efeitos da salinidade no desempenho germinativo das sementes de várias espécies têm sido estudados ao longo do tempo, aumentando consideravelmente o período de germinação pela presença de sais solúveis no solo. Os brassinosteróides são fitohormônios envolvidos no alongamento e divisão celular e devido a isto estão associados ao aumento na tolerância da planta aos estresses biótico e abiótico. Diante do exposto, conduziu-se este trabalho com o objetivo de avaliar o efeito na germinação sob estresse salino das sementes de arroz que receberam tratamento com 24-epibrassinolídeo. Para testar o proposto, foram utilizadas sementes das cultivares BRS Querência e BRS Bojurú suscetível e tolerante a salinidade, consecutivamente. O experimento foi constituído por cinco tratamentos, sendo um com água destilada (zero), um com solução de $100 \mathrm{mM}$ de $\mathrm{NaCl}$ e mais três tratamentos compostos por uma solução de 100 $\mathrm{mM}$ de $\mathrm{NaCl}$ complementada com 24-epibrassinolídeo nas concentrações 0,$01 ; 0,1$; e 1,0 $\mu \mathrm{M}$. As sementes das duas cultivares foram embebidas por duas horas nas respectivas soluções e avaliadas pelos seguintes testes: germinação, primeira contagem da germinação, índice de velocidade de germinação, condutividade elétrica (às 3 e 24 horas), comprimento e massa seca da parte aérea e da raiz. Os tratamentos compuseram um fatorial $2 \times 5$, ou seja, 2 cultivares e 5 soluções e o delineamento experimental utilizado foi inteiramente casualizado, com quatro repetições. As médias foram comparadas pelo teste de Tukey aos $5 \%$ de probabilidade. A cultivar BRS Querência teve a germinação e o vigor restabelecidos pela suplementação da solução salina com 24-epibrassinolídeo. As sementes da cultivar BRS Bojurú, não perderam seu percentual germinativo quando submetidas ao tratamento com solução de $100 \mathrm{mM}$ de $\mathrm{NaCl}$ e a adição de 24-epibrassinolídeo na concentração mais baixa, $0,01 \mu \mathrm{M}$, proporcionou incremento no potencial germinativo, porém, a concentração mais elevada reduziu a germinação das sementes de arroz desta cultivar. Pode-ser inferir que o 24-epibrassinolídeo é capaz de reverter o efeito do estresse salino em sementes de arroz, suscetíveis a salinidade, não atuando da mesma forma em cultivares mais tolerantes.
\end{abstract}

Termos para indexação: salinidade, vigor, viabilidade, brassinosteróides.

\section{PHYSIOLOGICAL QUALITY OF RICE SEEDS TREATED WITH SALINE SOLUTION AND 24- EPIBRASSINOLIDE}

ABSTRACT - The effects of salinity on the germination of seeds of various species have shown that the germination period increased significantly with the presence of soluble salts

${ }^{1}$ Submetido em 10/08/2009. Aceito para publicação em 01/11/2010. Parte da Dissertação de Mestrado do primeiro autor apresentada a UFPel.

${ }^{2}$ Bióloga, pós-graduanda do Departamento de Botânica, UFPel/IB, Caixa Postal: 354, CEP: 96010-900, Pelotas-RS, cristina_larre@yahoo.com.br
${ }^{3}$ Eng. Agr. Dr., Professor Titular, Departamento de Botânica, UFPel, Caixa postal 354 CEP: 96010-900, Pelotas,moraesdm@ufpel.tche.br; neilopes@ufpel.edu.br. 
in the soil. The brassinosteroids are hormones involved in plant elongation and cell division and are associated with the increased tolerance of plants to biotic and abiotic stresses. We evaluated the effect of 24-epibrassinolide on the germination of rice seeds subjected to salt stress using the Querencia and BRS Bojurú varieties, respectively susceptible and tolerant to salinity. The experiment consisted of five treatments: one with distilled water (zero), one with a solution of $100 \mathrm{mM} \mathrm{NaCl}$, and three treatments consisting of a solution of $100 \mathrm{mM} \mathrm{NaCl}$ supplemented with 24-in epibrassinolide concentrations of $0.01,0.1$, and $1.0 \mathrm{mM}$. The seeds of the two cultivars were soaked for two hours in the solutions and evaluated for: germination, first count germination, germination speed index, electrical conductivity (at 3 and 24 hours) and length and dry weight of shoot and root. The treatments comprised a factorial $2 \times 5$ : two cultivars and the five experimental solutions. The experimental design was completely randomized with four replications. Means were compared by the Tukey test $(\mathrm{p}<5 \%)$. The germination and vigor of the BRS Querencia were restored by supplementing the saline with 24-epibrassinolide. The percentage germination of the BRS Bojurú did not decrease when treated with a solution of 100 $\mathrm{mM} \mathrm{NaCl}$ and the addition of 24-epibrassinolide at the lower concentration, $0.01 \mathrm{mM}$, increased the germination potential. However, the highest concentration reduced germination in this rice variety. It can be concluded that the 24-epibrassinolide can reverse the effect of salt on rice seed which is susceptible to salinity but does not act in the same way in more tolerant cultivars.

Index terms: salinity, vigour, viability, brassinosteroids.

\section{INTRODUÇÃO}

A cultura do arroz é irrigada por inundação, podendo conduzir com o tempo à salinização de solos que não possuem drenagem adequada, tornando impraticável a continuidade do cultivo em certas áreas (Lima et al., 2004).

Os efeitos da salinidade no desempenho germinativo das sementes de várias espécies têm sido estudados ao longo do tempo, aumentando consideravelmente o período de germinação pela presença de sais solúveis no solo (Campos e Assunção, 1990). Em geral, tanto halófitas como glicófitas respondem de modo semelhante ao incremento na intensidade do estresse, reduzindo o número total de sementes germinadas e a velocidade de germinação (Lima et al., 2004).

O processo de germinação é caracterizado principalmente, pela absorção de água e mobilização de reservas da semente (Marcos Filho, 2005). A absorção de água é prejudicada pelo excesso de sais solúveis que reduzem o potencial hídrico do solo. Essa redução no potencial hídrico associada aos efeitos tóxicos dos sais interfere inicialmente no processo de absorção de água pelas sementes, influenciando na germinação (Barroso et al., 2010).

A menor absorção de água pelas sementes atua reduzindo a velocidade dos processos fisiológicos e bioquímicos da germinação e como resultados têmse a formação de plântulas com crescimento reduzido, caracterizado pela diminuição no comprimento da plântula e menor acúmulo de matéria seca (Silva et al., 2007). Em muitos casos a concentração de sais não atinge níveis osmóticos ou tóxicos capazes de prejudicar a absorção de água pelas plantas. No entanto, a concentração de íons diversos pode provocar interferências indiretas ao desenvolvimento normal do metabolismo (Zanandrea et al., 2006).

Os efeitos dos brassinosteróides são associados ao aumento na tolerância aos estresses que as plantas estão sujeitas aumentando a resistência a altas e baixas temperaturas, seca, salinidade e toxicidade por metais pesados (Anuradha e Rao, 2001).

Em arroz, o 24-epibrassinolídeo incrementou a resistência à temperaturas entre $1-5{ }^{\circ} \mathrm{C}$ e a tolerância foi associada com incremento na produção de ATP, aumento nos níveis de prolina e aumento na atividade enzimática, indicando que esse brassinosteróide está envolvido na estabilidade e osmorregulação (Rao et al., 2002). Enquanto a capacidade do 24-epibrassinolídeo em reverter o efeito inibitório causado, pela salinidade, na germinação de sementes de Eucalyptus camaldulensis Dehn. foi descrito por Sasse (2003). 
Diante do exposto, objetivou-se nesse trabalho avaliar o efeito do tratamento de sementes com solução salina e 24-epibrassinolídeo na qualidade fisiológica de sementes de arroz das cultivares BRS Querência e BRS Bojurú.

\section{MATERIAL E MÉTODOS}

O trabalho foi conduzido no Laboratório de Fisiologia de Sementes e em Casa de Vegetação pertencentes ao Departamento de Botânica, da Universidade Federal de Pelotas.

Utilizou-se sementes de arroz das cultivares BRS Bojurú e BRS Querência, procedentes da Estação Experimental de Terras Baixas (Embrapa - Clima Temperado).

O experimento foi constituído por cinco tratamentos, sendo um com água destilada (zero) e outro com solução de $100 \mathrm{mM}$ de $\mathrm{NaCl}$, mais três tratamentos que foram compostos pela solução de $100 \mathrm{mM}$ de $\mathrm{NaCl}$, a qual foi complementada com 24-epibrassinolídeo nas concentrações 0,$01 ; 0,1$; e $1,0 \mu \mathrm{M}$.

As sementes das duas cultivares utilizadas neste ensaio foram embebidas por duas horas nas respectivas soluções e avaliadas pelos seguintes testes: teste de germinação (TG) - realizado conforme especificado pelas Regras de Análise de Sementes (Brasil, 2009), utilizando 400 sementes, divididas em quatro repetições estatísticas. As sementes foram semeadas em papel toalha umedecido com quantidade de água destilada equivalente a duas vezes e meia a massa do substrato e colocadas para germinar em câmara de germinação à temperatura de $25 \pm 1{ }^{\circ} \mathrm{C}$. As avaliações foram realizadas aos 14 dias após a semeadura (DAS), sendo consideradas normais as plântulas que apresentaram sistema radicular bem formado e coleóptilo perfeito, com uma folha bem desenvolvida (plúmula) no interior ou emergido deste. Os resultados foram expressos em porcentagem de germinação; primeira contagem da germinação (PCG) - avaliação foi realizada no quinto DAS, juntamente com o teste de germinação, sendo consideradas germinadas as sementes cuja protrusão da radícula era maior ou igual a dois milímetros $(\mathrm{mm})$, e os resultados foram expressos em porcentagem de germinação; índice de velocidade de germinação (IVG) - determinado conjuntamente ao teste de germinação, conforme descrito por Vieira e Carvalho (1994), sendo efetuada a contagem do número de plântulas germinadas diariamente, até a estabilização do estande. O IVG foi calculado segundo a fórmula proposta por Maguirre (1962); condutividade elétrica (CE) quatro subamostras de 25 sementes, com suas massas previamente determinadas, foram embebidas durante duas horas em água, na solução salina $(100 \mu \mathrm{M}$ de $\mathrm{NaCl})$ e nas soluções de $100 \mu \mathrm{M}$ de $\mathrm{NaCl}$ complementada com 24-epibrassinolídeo nas concentrações 0,$01 ; 0,1$ e 1,0 $\mu \mathrm{M}$. Após a embebição nas diferentes soluções, as sementes provenientes de cada tratamento foram colocadas em becker, com capacidade de $200 \mathrm{~mL}$, contendo $80 \mathrm{~mL}$ de água deionizada e levados à câmara de germinação e mantidas à $20{ }^{\circ} \mathrm{C}$. A condutividade elétrica foi medida em condutivímetro Digimed CD-21 após três e 24 horas de embebição na água deionizada, de acordo com metodologia descrita por Krzyzanowski (1991). Os resultados foram expressos em $\mu \mathrm{S} \mathrm{m}^{-1} \mathrm{~g}^{-1} \mathrm{de}$ semente; comprimento da parte aérea e do sistema radicular (CPA e CR) - ao final do teste de germinação, 14 DAS, das plântulas consideradas normais foram selecionadas vinte plântulas por tratamento, de cada repetição, e utilizadas para determinar o comprimento da parte aérea e do sistema radicular medido por meio de uma régua graduada, sendo os resultados expressos em mm plântula ${ }^{-1}$; massa da matéria seca da parte aérea e das raízes (MSPA e MSR) - foi avaliada nas mesmas vinte plântulas utilizadas para aferir os comprimentos da parte aérea e das raízes. O material vegetal foi levado à estufa e seco a $70 \pm 2{ }^{\circ} \mathrm{C}$ até atingir massa constante e a massa seca determinada gravimetricamente. $\mathrm{O}$ valor da massa da matéria seca da parte aérea e das raízes foram divididos pelo número de plântulas utilizadas no teste e os resultados expressos em mg plântula ${ }^{-1}$;

O delineamento experimental utilizado foi inteiramente casualizado em esquema fatorial $(2 \times 5)$, sendo duas cultivares analisadas e cinco tratamentos, com quatro repetições estatísticas em cada tratamento. Realizouse análise de variância dos dados e as médias foram comparadas pelo teste de Tukey com 5\% de probabilidade, utilizando o software WinStat 2.0 (Machado e Conceição, 2003).

\section{RESULTADOS E DISCUSSÃO}

A porcentagem de germinação das sementes de arroz cultivar BRS Querência decresceu quando tratadas com solução de $100 \mu \mathrm{M}$ de $\mathrm{NaCl}$, contudo a adição de 24-epibrassinolídeo ao $\mathrm{NaCl}$, reverteu o efeito da salinidade sobre a germinação, restabelecendo a porcentagem de sementes germinadas com o aumento da concentração do hormônio (Tabela 1). 
TABELA 1. Porcentagem média de germinação (G\%), primeira contagem (PCG\%), e índice de velocidade de germinação (IVG) de sementes de arroz de duas cultivares, BRS Querência (BRS-Q) e BRS Bojurú (BRS-B), tratadas com $\mathrm{NaCl}(100 \mathrm{mM})$ e $\mathrm{NaCl}(100 \mathrm{mM})+24$-epibrassinolídeo a $0,01 \mu \mathrm{M}(\mathrm{EBR} 1)$, $\mathrm{NaCl}(100 \mathrm{mM})+24$-epibrassinolídeo a 0,1 $\mu \mathrm{M}$ (EBR2) e $\mathrm{NaCl}(100 \mathrm{mM})+24$-epibrassinolídeo a 1,0 $\mu \mathrm{M}($ EBR3).

\begin{tabular}{cccllll}
\hline \multirow{2}{*}{ Tratamentos } & \multicolumn{2}{c}{$\mathrm{G}(\%) *$} & \multicolumn{2}{c}{ PCG $(\%) *$} & \multicolumn{2}{c}{ IVG* } \\
\cline { 2 - 7 } & BRS-Q & BRS-B & BRS-Q & BRS-B & BRS-Q & BRS-B \\
\hline Zero & $88 \mathrm{Aa}$ & $87 \mathrm{Aab}$ & $87 \mathrm{Aa}$ & $86 \mathrm{Aa}$ & $17,0 \mathrm{Aa}$ & $15,1 \mathrm{Ba}$ \\
$\mathrm{NaCl}(100 \mathrm{mM})$ & $84 \mathrm{Ab}$ & $86 \mathrm{Aab}$ & $80 \mathrm{Bbc}$ & $85 \mathrm{Aab}$ & $14,6 \mathrm{Ab}$ & $14,4 \mathrm{Aab}$ \\
$\mathrm{NaCl}+\mathrm{EBR} 1$ & $85 \mathrm{Bab}$ & $89 \mathrm{Aa}$ & $79 \mathrm{Bc}$ & $83 \mathrm{Ab}$ & $16,5 \mathrm{Aa}$ & $13,9 \mathrm{Bb}$ \\
$\mathrm{NaCl}+\mathrm{EBR} 2$ & $85 \mathrm{Aab}$ & $87 \mathrm{Aab}$ & $82 \mathrm{ABb}$ & $85 \mathrm{Aab}$ & $16,3 \mathrm{Aa}$ & $13,5 \mathrm{Bb}$ \\
$\mathrm{NaCl}+\mathrm{EBR} 3$ & $88 \mathrm{Aa}$ & $85 \mathrm{Bb}$ & $86 \mathrm{Aa}$ & $79 \mathrm{Bc}$ & $17,2 \mathrm{Aa}$ & $11,3 \mathrm{Bc}$ \\
\hline $\mathrm{CV} \%$ & \multicolumn{3}{c}{3,658} & 3,094 & & 7,214 \\
\hline
\end{tabular}

*Médias seguidas de letras minúsculas distintas, na coluna, e letras maiúsculas na linha, diferem entre si pelo Teste Tukey em 5\% de probabilidade.

Os resultados dos testes de primeira contagem da germinação (PCG) e o índice de velocidade de germinação (IVG) para cultivar BRS Querência mostram que o processo de germinação foi mais lento em meio salino, e a aplicação do 24-epibrassinolídeo recuperou o índice de velocidade de germinação quando comparado ao tratamento com água. A primeira contagem da germinação, para esta cultivar, demonstrou que a aplicação da solução salina reduziu os valores de germinação neste período (PCG) e só se restabeleceu, equiparando-se ao tratamento com água, após a suplementação da solução salina com o 24epibrassinolídeo na maior concentração $(1,0 \mu \mathrm{M})$. Estes resultados mostram que o vigor das sementes da cultivar BRS Querência, considerada suscetível ao estresse salino, é mantido quando tratadas com a concentração mais elevada do 24-epibrassinolídeo.

As sementes da cultivar BRS Bojurú, não tiveram seu porcentual germinativo reduzido, em relação as que foram tratadas com água, quando tratadas com solução de $100 \mathrm{mM}$ de $\mathrm{NaCl}$, EBR 1, 2 e 3, contudo a germinação das sementes tratadas com EBR1 (89\%) foi superior aquelas tratadas com EBR3 (85\%). A salinidade, assim como os tratamentos com 24epibrassinolídeo, reduziram os valores da PCG em relação as sementes tratadas com água. Sendo que o tratamento EBR 3 teve efeito prejudicial significativo na PCG e diminuiu a germinação das sementes para $79 \%$. Os resultados do IVG avalidas nas sementes da cultivar BRS Bojurú demonstraram que a salinidade ocasionou pouca redução na velocidade da germinação, no entanto adição de 24-epibrassinolídeo, na concentração mais elevada, 1,0 $\mu \mathrm{M}$, reduz significativamente a velocidade de germinação e o resultado do IVG, como teste de vigor, demonstra que os tratamentos com as demais soluções do epibrassinolídeo contribuíram para ocasionar queda no vigor das sementes desta cultivar (Tabela 1).

O IVG é calculado de acordo com a velocidade com que a semente germina e quanto mais rápido isso ocorre, maior será o seu vigor, com isso podemos observar que as duas cultivares testadas tiveram redução do seu vigor em função da adição do sal. Entretanto, a cultivar BRS Querênciateveseuvigor restabelecidopelasuplementação da solução salina com 24-epibrassinolídeo, sugerindo que o 24-epibrassinolídeo é capaz de reverter o efeito do sal em sementes de arroz, suscetíveis a salinidade.

Os efeitos da salinidade podem estar relacionados tanto ao fator osmótico do sal, limitando a hidratação das sementes, quanto ao efeito tóxico do sal sobre o embrião e às células da membrana do endosperma (Duarte et al., 2006). Ainda pode ser atribuída à restrição imposta à divisão e ao alongamento celular, bem como, a mobilização das reservas indispensáveis a ocorrência do processo germinativo. A absorção de água é prejudicada pelo excesso de sais solúveis reduzindo o potencial hídrico do solo (Bewley e Black, 1985). A redução na absorção de água pelas sementes atua reduzindo a velocidade dos processos fisiológicos básicos (Tabelas 1) e bioquímicos e, com isso as plântulas resultantes desse meio, com umidade reduzida, possuem 
menor desenvolvimento, (Silva et al., 2007).

Em sementes de arroz tolerantes à salinidade, o 24-epibrassinolídeo não tem efeito sobre a germinação, enquanto que em sementes da cultivar suscetível à salinidade a aplicação do 24-epibrassinolídeo aumenta significativamente o porcentual de germinação, tanto em condições salinas ou não (Özdemir et al., 2004). Resultados semelhantes aos encontrados neste trabalho, com a cultivar BRS Querência, foram descritos por Anuradha e Rao (2001), onde verificaram redução considerável no efeito inibitório da salinidade sobre a germinação de sementes de arroz, quando a solução salina foi suplementada com 24-epibrassinolídeo. Assim como a aplicação do 24epibrassinolídeo é efetiva na indução da germinação de sementes de sorgo sob estresse hídrico (Vardhini e Rao, 2003); resulta em aumento significativo no percentual de germinação em Raphanus sativus L. (Anuradha e Rao, 2007) estressadas por calor, em trigo sob estresse hídrico (Vardhini e Rao, 2003) e em arroz (Anuradha e Rao, 2001) sob estresse salino.

De acordo com os resultados obtidos no teste de condutividade elétrica, às três e 24 horas de embebição, nas sementes de arroz cultivares BRS Querência e BRS Bojurú, tratadas com 24-epibrassinolídeo e solução salina (Tabela 2), observa-se que, após três e 24 horas de embebição, as sementes das duas cultivares tratadas apenas com solução salina tiveram o valor de condutividade elétrica superior ao controle (água). $\mathrm{O}$ aumento da condutividade elétrica com a adição de sal demonstrou que a salinidade ocasionou a desorganização das membranas celulares fazendo com que maior quantidade de eletrólitos fossem lixiviados em ambas as cultivares.

TABELA 2. Condutividade elétrica, com três e 24 horas de embebição, de sementes de arroz de duas cultivares, BRS Querência (BRS-Q) e BRS Bojurú (BRS-B), tratadas com NaCl (100 mM) e NaCl (100 mM) + 24epibrassinolídeo a 0,01 $\mu \mathrm{M}$ (EBR1), $\mathrm{NaCl}(100 \mathrm{mM})+24$-epibrassinolídeo a $0,1 \mu \mathrm{M}$ (EBR2) e $\mathrm{NaCl}$ (100 mM) + 24-epibrassinolídeo a1,0 $\mu$ M (EBR3).

\begin{tabular}{|c|c|c|c|c|}
\hline \multirow{3}{*}{ Tratamentos } & \multicolumn{4}{|c|}{$\mathrm{CE}^{*} \quad\left(\mu \mathrm{Sm}^{-1} \mathrm{~g}^{-1}\right)$} \\
\hline & \multicolumn{2}{|c|}{3 horas } & \multicolumn{2}{|c|}{24 horas } \\
\hline & BRS-Q & BRS-B & BRS-Q & BRS-B \\
\hline Zero & $2,94 \mathrm{Ab}$ & $2,22 \mathrm{Ac}$ & $8,53 \mathrm{Bb}$ & $9,25 \mathrm{Ac}$ \\
\hline $\mathrm{NaCl}(100 \mathrm{mM})$ & $6,75 \mathrm{Ba}$ & $8,50 \mathrm{Aa}$ & $11,98 \mathrm{Ba}$ & $15,87 \mathrm{Aa}$ \\
\hline $\mathrm{NaCl}+\mathrm{EBR} 1$ & $3,03 \mathrm{Bb}$ & $4,31 \mathrm{Ab}$ & $8,09 \mathrm{Ab}$ & $12,42 \mathrm{Bb}$ \\
\hline $\mathrm{NaCl}+\mathrm{EBR} 2$ & $4,20 \mathrm{Ab}$ & $4,72 \mathrm{Ab}$ & $9,48 \mathrm{Ab}$ & $11,70 \mathrm{Bb}$ \\
\hline $\mathrm{NaCl}+\mathrm{EBR} 3$ & $3,88 \mathrm{Bb}$ & $4,73 \mathrm{Ab}$ & $8,67 \mathrm{Ab}$ & $11,98 \mathrm{Bb}$ \\
\hline
\end{tabular}

*Médias seguidas de letras minúsculas distintas, na coluna, e letras maiúsculas na linha, diferem entre si pelo Teste Tukey em 5\% de probabilidade.

Nas sementes da cultivar BRS Querência, a suplementação da solução salina com o 24-epibrassinolídeo reduziu os valores de condutividade elétrica, sugerindo que nesta cultivar o fitohormônio contribuiu para a reorganização das membranas após o período inicial de embebição (Tabela 2). Na cultivar BRS Bojurú, tolerante a salinidade, a reversibilidade dos resultados de condutividade elétrica após a embebição na solução salina suplementada com 24-epibrassinolídeo foi ainda mais significativo, indicando que o 24-epibrassinolídeo possa estar envolvido na estabilidade das membranas celulares em condições de estresse, tanto em cultivares mais suscetíveis como nas mais tolerantes a salinidade.

A presença de altos níveis de íons em não halófitas pode exercer efeitos adversos na permeabilidade das membranas (Munns, 2002), o que possivelmente tenha contribuído para a grande redução no percentual de germinação nas sementes da cultivar BRS Querência, na presença da solução salina (Tabela 1).

Os brassinosteróides, em geral, melhoram a resposta ao estresse por estarem envolvidos na alteração das estruturas e da permeabilidade das membranas celulares, em condições de estresse (Hamada, 1986) e por estarem também envolvidos na ativação dos mecanismos de 
proteção contra estresses oxidativos (Anuradha e Rao, 2007).

O comprimento das raízes nas plântulas de arroz das duas cultivares, foi inibido pela presença de $\mathrm{NaCl}$, sendo essa redução significativamente mais drástica na cultivar BRS Querência. No entanto, a adição de 24-epibrassinolídeo na solução com $\mathrm{NaCl}$ reverteu os efeitos deletérios da salinidade, sobre o crescimento das raízes, nas duas cultivares (Tabela 3 ).

TABELA 3. Comprimento da raiz (CR) e da parte aérea (CPA) de plântulas, provenientes do teste de germinação de sementes de arroz de duas cultivares, BRS Querência (BRS-Q) e BRS Bojurú (BRS-B), tratadas com $\mathrm{NaCl}(100 \mathrm{mM})$ e $\mathrm{NaCl}(100 \mathrm{mM})+$ 24-epibrassinolídeo a 0,01 $\mu \mathrm{M}$ (EBR1), NaCl (100 mM) + 24epibrassinolídeo a 0,1 $\mu \mathrm{M}(\mathrm{EBR} 2)$ e $\mathrm{NaCl}(100 \mathrm{mM})+24$-epibrassinolídeo a 1,0 $\mu \mathrm{M}$ (EBR3).

\begin{tabular}{ccrrc}
\hline \multirow{2}{*}{ Tratamentos } & \multicolumn{2}{c}{ CR $\left(\mathrm{mm} \mathrm{plântula}^{-1}\right)^{*}$} & \multicolumn{2}{c}{ CPA $\left.(\mathrm{mm} \text { plântula })^{-1}\right)^{*}$} \\
\cline { 2 - 5 } & BRS-Q & BRS-B & BRS-Q & BRS-B \\
\hline Zero & $118,3 \mathrm{Ab}$ & $113,3 \mathrm{Ba}$ & $105,8 \mathrm{Ab}$ & $95,8 \mathrm{Ba}$ \\
$\mathrm{NaCl}(100 \mathrm{mM})$ & $73,2 \mathrm{Bd}$ & $99,0 \mathrm{Ab}$ & $72,3 \mathrm{Bc}$ & $83,6 \mathrm{Ab}$ \\
$\mathrm{NaCl}+\mathrm{EBR} 1$ & $108,5 \mathrm{Bc}$ & $114,6 \mathrm{Aa}$ & $101,6 \mathrm{Ab}$ & $96,5 \mathrm{Ba}$ \\
$\mathrm{NaCl}+\mathrm{EBR} 2$ & $119,5 \mathrm{Ab}$ & $118,5 \mathrm{Aa}$ & $127,6 \mathrm{Aa}$ & $93,5 \mathrm{Ba}$ \\
$\mathrm{NaCl}+\mathrm{EBR} 3$ & $130,8 \mathrm{Aa}$ & $15,5 \mathrm{Ba}$ & $131,7 \mathrm{Aa}$ & $84,5 \mathrm{Bb}$ \\
\hline $\mathrm{CV} \%$ & \multicolumn{2}{c}{4,902} & & \\
\hline
\end{tabular}

*Médias seguidas de letras minúsculas distintas, na coluna, e letras maiúsculas na linha, diferem entre si pelo Teste Tukey em 5\% de probabilidade.

O comprimento da parte aérea das plântulas de arroz das cultivares BRS Querência e BRS Bojurú foram diminuído significativamente pela salinidade (100 mM de $\mathrm{NaCl}$ ) quando comparado ao tratamento com água (Tabela 3). A cultivar BRS Querência teve um decréscimo mais significativo devido à salinidade, porém, apresentou uma recuperação mais significativa quando tratada com 24-epibrassinolídeo. A cultivar BRS Querência teve o crescimento da parte aérea restabelecido pela aplicação do 24-epibrassinolídeo à solução salina, na concentração mais baixa, $0,01 \mu \mathrm{M}$, e apresentou maior parte aérea de plântula, comparado ao tratamento controle, quando foram utilizadas concentrações mais elevadas de 24-epibrassinolídeo, 0,1 e $1,0 \mu \mathrm{M}$ (Tabela 3 ), demonstrando o envolvimento do 24-epibrassinolídeo no crescimento em condições de estresse. A cultivar BRS Bojurú teve o restabelecimento da condição inicial (tratamento com água) quando as concentrações de 24-epibrassinolídeo utilizadas foram menores $(0,01$ e $0,1 \mu \mathrm{M})$, mas quando aplicado na maior concentração $(1,0 \mu \mathrm{M}) \mathrm{o}$ crescimento da parte aérea ficou próximo ao das plântulas tratadas com $\mathrm{NaCl}$ $100 \mathrm{mM}$. Isto sugere que em cultivares mais tolerantes, baixas concentrações de 24-epibrassinolídeo são suficientes para reduzir os efeitos da salinidade, no que tange ao crescimento da parte aérea.

Em cultivares suscetíveis, o aumento da concentração do fitohormônio pode ser efetivo na indução do crescimento. Aumento na altura das plântulas foi atribuído ao 24-epibrassinolídeo em várias condições de estresse abióticos como em Raphanus sob estresse por cádmio (Hayat et al., 2006 ), em feijão sob estresse por alumínio (Abdulahi et al., 2003; Vardhini e Rao, 2003), em arroz (Anuradha e Rao, 2001) e sorgo (Vardhini e Rao, 2003) sob estresse osmótico.

Está bem estabelecido que a salinidade reduz o crescimento e muitos processos fisiológicos como consequência de alterações metabólicas induzidas pelo sal (Silva et al., 2007). A síntese de ácidos nucléicos e proteínas solúveis são processos metabólicos ativados durante o crescimento, e a capacidade do 24-epibrassinolídeo em reverter os efeitos da salinidade e, em alguns casos, proporcionar incremento relevante em alguns processos fisiológicos, refletindo em altos níveis desses metabólitos (Anuradha e Rao, 2001).

A matéria seca das raízes das cultivares BRS Querência e BRS Bojurú foi reduzida nas plântulas tratadas com NaCl $100 \mathrm{mM}$ (Tabela 4). No entanto, os valores de massa seca acumulada nas raízes aumentaram a níveis próximos aos do controle (água) com a 
suplementação da solução salina com 24-epibrassinolídeo a $0,01 \mu \mathrm{M}$ nas duas cultivares. Na cultivar BRS Querência, a aplicação do 24-epibrassinolídeo, nas concentrações de 0,1 e $1,0 \mu \mathrm{M}$, foi capaz de incrementar o acúmulo de massa seca da raiz a níveis significativamente superiores aos do controle (Tabela 4).

TABELA 4. Massa seca da raiz (MSR) e da parte aérea (MSPA) de plântulas, provenientes do teste de germinação de sementes de arroz de duas cultivares, BRS Querência (BRS-Q) e BRS Bojurú (BRS-B), tratadas com $\mathrm{NaCl}(100 \mathrm{mM})$ e $\mathrm{NaCl}(100 \mathrm{mM})+24$-epibrassinolídeo a 0,01 $\mu \mathrm{M}$ (EBR1), NaCl (100 mM) + 24epibrassinolídeo a 0,1 $\mu \mathrm{M}$ (EBR2) e NaCl (100 mM) + 24-epibrassinolídeo a1,0 $\mu$ M (EBR3).

\begin{tabular}{ccccc}
\hline \multirow{2}{*}{ Tratamentos } & \multicolumn{2}{c}{ MSR $\left(\mathrm{mg} \text { plântula }{ }^{-1}\right)^{*}$} & \multicolumn{2}{c}{ MSPA(mg plântula $)^{*}$} \\
\cline { 2 - 5 } & BRS-Q & BRS-B & BRS-Q & BRS-B \\
\hline Zero & $41,3 \mathrm{Bc}$ & $58,2 \mathrm{Aa}$ & $38,9 \mathrm{Bc}$ & $41,2 \mathrm{Ab}$ \\
$\mathrm{NaCl}(100 \mathrm{mM})$ & $31,3 \mathrm{Be}$ & $53,7 \mathrm{Ac}$ & $31,6 \mathrm{Be}$ & $40,9 \mathrm{Ab}$ \\
$\mathrm{NaCl}+\mathrm{EBR} 1$ & $39,2 \mathrm{Bd}$ & $58,1 \mathrm{Aa}$ & $36,6 \mathrm{Bd}$ & $42,5 \mathrm{Aa}$ \\
$\mathrm{NaCl}+\mathrm{EBR} 2$ & $46,5 \mathrm{Bb}$ & $7,2 \mathrm{Aab}$ & $44,5 \mathrm{Ab}$ & $42,1 \mathrm{Ba}$ \\
$\mathrm{NaCl}+\mathrm{EBR} 3$ & $48,5 \mathrm{Ba}$ & $56,3 \mathrm{Ab}$ & $47,1 \mathrm{Aa}$ & $41,5 \mathrm{Bab}$ \\
\hline $\mathrm{CV} \%$ & \multicolumn{3}{c}{3,560} & \multicolumn{2}{c}{2,592} \\
\hline
\end{tabular}

*Médias seguidas de letras minúsculas distintas, na coluna, e letras maiúsculas na linha, diferem entre si pelo Teste Tukey em 5\% de probabilidade.

A matéria seca da parte aérea foi reduzida significativamente pela presença do $\mathrm{NaCl} 100 \mathrm{mM}$ na cultivar BRS Querência, em relação ao tratamento com água. As três diferentes concentrações, 0,$01 ; 0,1$ e 1,0 $\mu \mathrm{M}$ de 24-epibrassinolídeo utilizadas, foram eficientes em reverter os efeitos negativos da salinidade. E, as concentrações mais elevadas, 0,1 e $1,0 \mu \mathrm{M}$ conseguiram incrementar significativamente o acúmulo de massa seca na parte aérea em relação ao controle (Tabela 4). A cultivar BRS Bojurú não foi afetada pela condição salina, comparada com a água, e a aplicação do 24epibrassinolídeo nas concentrações 0,01 e $0,1 \mu \mathrm{M}$ foram capazes de incrementar esta variável. No entanto, a concentração mais elevada do 24-epibrassilolídeo não teve qualquer efeito sobre o acúmulo de massa seca na parte aérea desta cultivar (Tabela 4).

$\mathrm{O}$ incremento das massas fresca e seca em Raphanus sativus L. (Anuradha e Rao, 2007) tratadas com elevados teores de cádmio foi atribuído a aplicação de 24-epibrassinolídeo, assim como em arroz crescido sob estresse salino (Anuradha e Rao, 2001). O acúmulo de biomassa na parte aérea das plântulas da cultivar BRS Querência foi reduzido pela salinidade, incrementando a massa seca em função do aumento da concentração de 24-epibrassinolídeo utilizada (Tabela 4). Entretanto, na cultivar BRS Bojurú a salinidade não reduziu a biomassa acumulada na parte aérea e esta não foi alterada pela aplicação do hormônio (Tabela 4).

Uma das explicações mais aceita para a inibição do crescimento pelo sal é o desvio de energia do crescimento para a manutenção, sendo que a diminuição da massa seca pode refletir o custo metabólico de energia, associado à adaptação a salinidade e redução do ganho de carbono (Richardson e McCree, 1985). Podendo ser incluído nestes processos a regulação do transporte e distribuição iônica em vários órgãos e dentro das células, a síntese de solutos orgânicos para osmorregulação e a manutenção da integridade das membranas celulares. Assim a menor redução no crescimento no genótipo tolerante ocasionada pela salinidade pode estar associada ao menor custo energético para osmorregulação, conseguido por meio da acumulação e da compartimentalização de solutos inorgânicos no vacúolo e solutos orgânicos no citoplasma.

O 24-epibrassinolídeo também é reconhecido por restabelecer ou induzir a germinação e todas as características de crescimento sob estresse salino em Eucalyptus (Sasse et al.,2003) e arroz (Anuradha e Rao, 2001; Anuradha e Rao, 2003), em trigo e sorgo sob estresse hídrico (Vardhini e Rao, 2003) e arroz, tomate e abóbora (Anuradha e Rao, 2001 ) sob estresse por frio, além de aumentar a tolerância das plântulas sob estresse 
por metais pesados como, cádmio em Brassica juncea L. Czern. (Hayat et al., 2006) e Raphanus sativus L. (Anuradha e Rao, 2007) e alumínio em Vigna radiata L. Wilczek (Ali et al., 2008).

Em geral, a aplicação do 24-epibrassinolídeo foi positiva, principalmente no genótipo suscetível a salinidade, quando comparado com as plântulas não tratadas (controle) ou com plântulas tratadas com $\mathrm{NaCl}$ $100 \mathrm{mM}$. A aplicação do brassinosteróide normalmente provoca uma resposta positiva em virtude deste fitohormônio estar envolvido na modificação da estrutura e permeabilidade na membrana em situação de estresse (Hamada, 1986), promovendo a atividade do sistema de defesa antioxidante. $\mathrm{O}$ efeito cumulativo da modificação de todos estes processos incrementa o crescimento da plântula, principalmente em condição de estresse.

\section{CONCLUSÕES}

Na cultivar BRS Querência, suscetível à salinidade, a exposição ao $\mathrm{NaCl}$ reduz a viabilidade e o vigor das sementes, porém, a aplicação de 24-epibrassinolídeo restabelece ou incrementa a qualidade fisiológica e as características de crescimento.

$\mathrm{Na}$ cultivar BRS Bojurú, tolerante à salinidade, a suplementação da solução salina com o 24-epibrassinolídeo nas concentrações mais elevadas reduz o vigor das sementes.

\section{REFERÊNCIAS}

ABDULlAHI, B.A.; GU X.; GAN Q.; YANG Y. Brassinolide amelioration of aluminium toxicity in mung bean seedling growth, Journal of Plant Nutrition, v.26, p.1725-1734, 2003.

ALI, B.; HASAN, S.A.; HAYAT, S.; HAYAT, Q.; YADAV, S.; FARIDUDDIN, Q.; AHMAD, A.A. Role for brassinosteroids in the amelioration of aluminium stress through antioxidant system in mung bean (Vigna radiata L. Wilczek). Environmental and Experimental Botany, v.62, p.153-159, 2008.

ANURADHA, S.; RAO, S.S.R. Effect of brassinosteroids on salinity stress induced inhibition of seed germination and seedling growth of rice (Oryza sativa L.). Plant Growth Regulation, v.33, p.151-153, 2001.

ANURADHA, S.; RAO, S.S.R. Aplication of brassinosteroids to rice seeds (Oryza sativa L.) reduced the impact of salt stress on growth, prevented photosynthetic pigment loss and increased nitrate reductase activity. Plant Growth Regulation, v.40, p.29-32, 2003.

ANURADHA, S.; RAO, S.S.R. The effect of brassinosteroids on radish (Raphanus sativus L.) seedlings growing under cadmium stress. Plant Soil Environment, v.53. n.11, p.465-472, 2007.

BARROSO, C.M.; FRANKE, L.B.; BARROSO, I.B. Substrato e luz na germinação das sementes de rainha-doabismo. Horticultura Brasileira, v.28, n.2, p.236-240, 2010.

BEWLEY, J.D.; BLACK, M. Seeds: Physiology of development and germination, New York: Plenum Press, 1985. 367p.

BRASIL. Ministério da Agricultura, Pecuária e Abastecimento. Regras para análise de sementes. Ministério da Agricultura, Pecuária e Abastecimento. Secretaria de Defesa Agropecuária. Brasília, DF: Mapa/ ACS, 2009. 395p.

CAMPOS, I.S.; ASSUNÇÃO, M.V. Efeito do cloreto de sódio na germinação e vigor de plântulas de arroz. Pesquisa Agropecuária Brasileira, v.25, n.6, p.837-843, 1990.

DUARTE, G.L; LOPES, N.F.; MORAES, D.M.; SILVA, R.N. Physiological quality of wheat seeds submitted to saline stress. Revista Brasileira de Sementes, v.28, n.1, p.122-126, 2006.

HAMADA K. Brassinolide: some effects of crop cultivations. Conf. Proc. Int. Seminar Tokyo, Japan. Plant Growth Regulation, v.15, p.65-69, 1986.

HAYAT, S.; ALI, B.; AHMAD, A. Response of Brassica juncea to 28-homobrassinolide grown from the seeds exposed to salt stress. Journal of Plant Biology, v.33, p.169-174, 2006.

KRZYZANOWSKI, F.C.; FRANÇA NETO, J.B.; HENNING, A.A. Relato dos testes de vigor para as grandes culturas. Informativo ABRATES, v.1, n.2, p.1550, 1991.

LIMA, M.G.S.; LOPES, N.F.; BACARIN, M.A.; MENDES. C.R. Efeito do estresse salino sobre a concentração de pigmentos e prolina em folhas de arroz. Bragantia, v.63, n.3, p.335-340 2004.

MACHADO, A.A.; CONCEIÇÃO, A.R. Sistema de análise estatística para Windows. Winstat. Versão 2.0. UFPel, 2003.

MAGUIRRE, J.D. Speed of germination aid in selection and evaluation for seedling and vigour. Crop Science, v.2, n.2, p.176-177, 1962. 
MARCOS FILHO, J. Fisiologia de sementes de plantas cultivadas. Piracicaba: Fealq, 2005, 495p.

MUNNS, R. Comparative physiology of salt and water stress. Plant, Cell and Environment. v.25, p.239-250, 2002.

ÖZDEMIR, F.; BOR, M.; DEMIRAL, T.; TÜRKAN, I. Effects of 24-epibrassinolide on seed germination, seedling growth, lipid peroxidation, praline content and antioxidative system of rice (Oryza sativa L.) under salinity stress Plant Growth Regulation, v.42, n.3, p.203-211, 2004.

RAO, S.S.R.; VARDHINI, B.V.V.; SUJATHA, E.; ANURADHA S. Brassinosteroids-A new class of phytormones. Current Science, v.82, n.10, p.1239-1245, 2002.

RICHARDSON, S.G.; McCREE, K.J. Carbon balance and water relations of sorghum exposed to salt and water stress. Plant Physiology, v.79, n.11, p.1015-1020, 1985.
SASSE, J.M. Physiological actions of brassinosteroids: an update. Journal of Plant Growth Regulation, v.22, p.276-288, 2003.

SILVA, R.N.; LOPES, N.F.; MORAES, D.M; PEREIRA, A.L.; DUARTE, G.L. Physiological quality of barley seeds submitted to saline stress. Revista Brasileira de Sementes, v.29, n.1, p.40-44, 2007.

VARDHINI, B.V.; RAO, S.S.R. Amelioration of osmotic stress by brassinosteroids on seed germination and seedling growth of three varieties of sorghum. Plant Growth Regulation, v.41, n.1, p.25-31, 2003.

VIEIRA, R.D.; CARVALHO, N.M. Testes de vigor em sementes. Jaboticabal: FUNEP, 1994. 164p.

ZANANDREA, I.; NASSI, F.L.; TURCHETTO, A.C.; BRAGA, E.J.B.; PETERS, J.A.; BACARIN, M.A. Efeito da salinidade sob parâmetros de fluorescência em Phaseolus vulgaris Revista Brasileira de Agrociência, v.12, n.2, p.157-161, 2006. 